\title{
Kyphosis and Review of the Literature
}

\section{Kifoz ve Literatürün Gözden Geçirilmesi}

\author{
Onur YAMAN ${ }^{1}$, Sedat DALBAYRAK ${ }^{2}$ \\ ${ }^{1}$ Tepecik Education and Training Hospital, Clinic of Neurosurgery, Izmir, Turkey \\ ${ }^{2}$ Neurospinal Academy, Department of Neurosurgery, Istanbul, Turkey
}

Corresponding Author: OnurYAMAN / E-mail: dronuryaman@yahoo.com

\begin{abstract}
AIM: The term kyphosis is used to describe the spinal curve that results in an abnormally rounded back. Kyphosis may develop due to trauma, developmental anomalies, degenerative disc disease, inflammatory diseases, and infectious diseases and also iatrogenic. The aim of this paper is to review the etiopathognesis and the treatment management of kyphosis.

METHODS: A search in the National Library of Medicine (Pubmed) database using key word 'kyphosis' and was made. For the literature review, papers concerning etiopathogenesis, classification and treatment were selected among these papers.

RESULTS: A search in the National Library of Medicine (Pubmed) database using key word 'kyphosis' yielded 7506 papers published between 1916 and 2013. The main papers about kyphosis were congenital, Scheuermann, tumour related, neuromuscular, posttraumatic, infectionrelated, iatrogenic kyphosis.

CONCLUSIONS: Every patient with kyphosis should be treated based on her/his current state and needs. It should always be remembered that the patients with negative sagittal balance can compensate it with the hip flexion but it is far more difficult to compensate the positive sagittal balance. The main goal of surgery to treat the kyphotic patients is to correct the sagittal curve and also restore a spinal balance within an acceptable range above the hips and knees.
\end{abstract}

KEYWORDS: Kyphosis, Management, Review

\section{Öz}

AMAÇ: Omurganın normal diziliminin bozulup anormal yuvarlak şekil almasına (kamburluk) kifoz denir. Kifoz travmaya, gelişim anomalilerine, dejenertaif disk hastalığına, enflamatuvar ve enfeksiyöz nedenlere bağlı olarak gelişebileceği gibi, iyatrojenik olarak da ortaya çıkabilir. Bu çalışmanın amacı, kifoz nedenlerini ve kifozu olan hastaların tedavi yönetimini incelemektir.

YÖNTEM: Elektronik arama motoru Pubmed'de 'kyphosis' kelimesi ile arama yapıldı. Değerlendirme için etiyopatogonez, sınıflama ve tedavi ile ilgili olan makaleler derleme makalesine dahil edildi.

BULGULAR: Elektronik arama motoru Pubmed'de 'kyphosis' kelimesi ile arama yapıldığında 1916 ve 2013 yılları arasında toplam 7506 makale bulundu. Kifozla ilgili yazıların büyük kısmının konjenital, Scheuermann, tümörle ilişkili, nöromüsküler, travma sonrası, enfeksiyona bağlı ve iatrojenik kifozla ilişkil olduğu görüldü.

SONUÇ: Kifozu olan her hasta kendi şartları içinde ve hastanın ihtiyaçlarına göre değerlendirilmelidir. Negatif sagital balansa sahip hastanın kompansasyon mekanizmaları ile kendini dengelemesi daha kolayken pozitif sagital balansa sahip hastaların dengeyi sağlaması daha zordur. Kifotik deformiteye sahip hastaların cerrahi tedavisindeki temel amaç, eğriliği düzeltmek ve omurganın dengesini kabul edilebilir sınırlara getirerek kalça ve diz üzerinde durabilecek hale getirmektir.

ANAHTAR SÖZCÜKLER: Kifoz, Yönetim, Derleme

\section{INTRODUCTION}

The term kyphosis is used to describe the spinal curve that results in an abnormally rounded back. Kyphosis can occur at any age. 7456 papers were found when the word 'kyphosis' was searched on 'Pubmed' search engine. The majority of these papers studied kyphosis were related with scoliosis. It was understood that kyphosis was studied in addition to the other deformities in the papers related to the etiology and surgery of kyphosis with some exceptional cases.

\section{What is the normal range of thoracic kyphosis?}

The sagittal alignment of the spine always changes during the period starting from birth to old ages. The whole spine remains in the kyphotic posture extending from occipital to the sacrum at birth; whereas when one starts standing in the upright posture, first lordosis occurs in the lumbar region and then kyphosis occurs in the thoracic region.

Bernhardt et al. reported that the angle of kyphosis ranged from 9 to 53 degrees on average measured from the level above T3 and the one level below T12; while Stagnara et al. reported that the angle values ranged from 30 to 50 degrees measured from the superior endplate of T4 and the inferior endplate of the vertebrae in the middle (in general L1) (9, 61). Boulay found values ranging from 33.2 to 83.5 degrees 
measured by using actual Cobb angles (angle between the superior end plate of the upper end cranial vertebrae with the biggest curvature and the inferior end plate of the lower end vertebrae with the biggest curvature) (14). The Scoliosis Research Society (SRS) reported values ranging from 10 to 40 degrees measured from the superior endplate of T5 and inferior endplate of T12 (45). Thoracic kyphosis occurs more predominantly in males than in females (9.6\%). Thoracic kyphosis progresses during the adolescent growth spurt in girls while it decreases following the deceleration of growth (15).

Lumbar lordosis is larger than the thoracic kyphosis. Lumbar lordosis is more predominant in women. Bernhard et al. found values ranging from 14 to 69 degrees measured from the inferior endplate of T12 and inferior endplate of L5 (9). Stagnara reported the lumbar lordosis values to be between 32 and 84 degrees (61). While the actual Cobb angles reported by Bouley ranged from 44.8 to 87.2 degrees, SRS reported such values as 40-60 degrees $(14,45)$.

The spine in the sagittal balance can stand straight by minimizing the energy consumption. The vertical line drawn from the plumb line of $\mathrm{C} 7$ should intersect the posterosuperior corner of S1 (45). An unbalanced spine cannot stand on the femoral head and sacrum. Positive sagittal balance is achieved when the plumb line falls in the front of the femoral head; whereas spine falling behind the femoral head causes negative sagittal balance (40).

The location of the apical vertebrae is as important as the degree of the kyphosis. The impact of the thoracolumbar kyphosis on the sagittal balance is greater than that of the thoracic kyphosis. The pelvic incidence parameter was first described by Duval Beaupere (38). Pelvic incidence is the only pelvic parameter that remains unchanged during one's whole life. Pelvic incidence is the angle between a line drawn perpendicular to the superior endplate of S1 and another line connecting the femoral head to the centre of the sacrum. Pelvic incidence shows the relation between the spine and the pelvis (38). Lumbar lordosis is greater than the pelvic incidence by 10 degrees in a spine with sagittal balance.

\section{Etiology of Kyphosis}

Trauma and developmental anomalies, degenerative disc disease, inflammatory diseases, and infectious diseases are the causes of kyphosis. Considering the degree of kyphosis; it is divided into two types: low degree (such as postural roundback) and high degree (angular gibbus deformity, congenital kyphosis, Pott disease and best known form which is Scheuermann). Kyphosis may also develop due to the muscular and neuromuscular diseases in addition to the above mentioned causes. Cerebral palsy, muscular dystrophy, spinal muscular atrophy and myelomeningocele, neurofibramatosis and connective tissue disease, Paget disease, tumours and surgery may also cause kyphosis. The pathologies that may cause kyphosis are presented according to the number of the papers studying it (Table I).

\section{Scheuermann Kyphosis (Juvenile kyphosis)}

\section{Epidemiology}

Scheuermann disease was defined for the first time by a Danish radiologist Holger Werfel Scheuermann as 'Osteochondritis deformans juvenilis dorsi'. It is characterized as a rigid kyphosis predominantly in young adults caused by the osteochondritis of the secondary ossification centres (57). This might affect a few spinal segments while it might also affect the whole spine. In general, it occurs predominantly in children between 13 and 16 years of age. Patients are usually taller than their peers. Its incidence in the USA is $0.4-8 \%$. It occurs more often in boys than in girls by $2 / 1-7 / 1$.

\section{Pathophysiology}

The etiology and pathogenesis of kyphosis are not exactly known. Scheuermann Disease was reported to be caused by the disturbances in the vertebral epiphyseal growth (57). A mosaic structure in the endplate of the vertebrae and growth cartilage was mentioned (23). It was stated that there were abundant proteoglycans, and the quantity of the collagen was low in the structure of the bone. There is a 'growth deficiency' in some parts of the bone rather than a destruction. This causes the wedging and kyphosis of the vertebrae in later phases.

Table I: Etiology of Kyphosis

\begin{tabular}{|l|c|}
\hline Etiology of Kyphosis & Number of Papers \\
\hline Congenital kyphosis & 729 \\
\hline Scheuermann Kyphosis & 633 \\
\hline Tumour-related Kyphosis & 597 \\
\hline $\begin{array}{l}\text { Kyphosis developing due to neuro- } \\
\text { muscular diseases }\end{array}$ & 159 \\
\hline Posttraumatic Kyphosis & 75 \\
\hline Infection-related kyphosis (Pott) & 75 \\
\hline Postlaminectomy iatrogenic kyphosis & 58 \\
\hline Skeletal Dysplasia & 49 \\
\hline
\end{tabular}

Table II: Scheuermann Classification

Type 1 (Classic)

More than 5 degrees of wedging of one or more vertebrae in the thoracic or thoracolumbar region

End plate irregularities

Narrowing of the disc space

Thoracic or thoracolumbar kyphosis

Type 2 (Lumbar) Atypical

Endplate irregularities in the lumbar or thoracolumbar region

Increased sagittal diameters of the vertebral bodies

Reduction in the disc space 


\section{Classification}

Although Sorenson proposed the initial criteria for the diagnosis of the Scheuermann Disease, they were finalized by Edgren et al. and followed by the inputs by Blumenthal et al. $(12,23,60)$. Scheuermann kyphosis usually occurs in the thoracic region (Type I) whereas it may also occur in the lumbar region (Type II) (Table II).

\section{Clinical Findings}

1. Pain: Pain occurs on the apical area after sitting for a long time and due to motion. Pain also decreases when growth stops. People with Type 2 Scheuermann kyphosis feel more pain than those with Type 1.

2. Deformity: It's usually recognized during school age. Lumbar lordosis and cervical lordosis may increase to balance the kyphosis.

\section{Treatment}

\section{Conservative}

Scheuermann kyphosis often does not require surgery. Brace wear and physical therapy should be proposed for adolescent patients with 55-degree thoracic kyphosis or 40-degree thoracolumbar kyphosis until they reach maturity. Brace wear does not have any impact on patients with the Risser sign 4 or 5 (54). Braces should be used longer than 20 hours a day. Brace wear should be continued for a minimum of 18 months. Brace wear can be reduced to 12-14 hours a day during the period when a correction of kyposis is achieved. Thoracolumbosacral orthosis should be preferred as the brace type to be used. It is appropriate for the adolescents as it is invisible under the clothes (53).

\section{Surgical Indications}

The absolute and only indication for surgery in Scheuermann disease is the neurological deficit arising due to the thoracic disc or pathology. Other surgical indications are relative.

\section{Relative Indications}

1. Surgery should be considered for symptomatic patients when the thoracic kyphosis exceeds 80 degrees and thoracolumbar kyphosis exceeds 65 degrees $(15,40)$.

1. Pain that is not relieved by non-operative methods.

2. Rapid curve progression.

\section{Postlaminectomy Kyphosis}

58 papers were found when the words 'postlaminectomy' and 'kyphosis' were searched on Pubmed search engine. All papers reported the development of postlaminectomy cervical kyphosis.

Laminectomy is indicated for patients with multiple cervical compressions or tumours $(1,28)$. The risk of developing kyphosis after the extensive laminectomy increases. 36\% of the load is distributed to the forearm while $65 \%$ is carried by the facets in the posterior column in the cervical region. For this reason, it should be remembered that the stability is disrupted when the posterior tension band (of the interspinuous ligaments, ligamentum flavum and nuchal ligament) is damaged. Bell et al. reported that $38 \%$ of the children developed kyphosis after laminectomy (8). Raimondi and Yasuko reported that kyphosis might develop postoperatively especially in children without any facet damage $(77,51)$. In some series of studies, postlaminectomy kyphosis development rate in children was reported to be $100 \%(31,22)$. Ebstein recommended that maximum $1 / 3$ of the facets in the cervical region should be removed in adults (24). Zdeblick also reported that removal of more than $50 \%$ of the facets caused cervical instability (79).

The patients should be selected accurately for laminectomy to avoid the development of postlaminectomy kyphosis. The presence of preoperative lordosis (10 degrees and greater), lack of instability findings in the flexion and extension radiograms and preservation of the facets during the surgery will reduce the likelihood to develop postlaminectomy kyphosis. The risk of postlaminectomy kyphosis is doubled in patients without cervical lordosis. Posterior fusion following decompression is recommended in cases when the facets could not be protected $(52,56)$. McAllister et al. proposed fusion for cases where $40 \%-50 \%$ of the facets are removed (41). The most common fusion method today is to use the lateral mass screws. The rate of the instrumented posterior cervical fusion goes up to $95 \%$ (52). Kumar et al. reported that kyphosis did not develop in any of the patients they treated with cervical laminectomy and fusion during the follow-up period (34).

\section{Surgery}

Three strategies were proposed for the postlaminectomy kyphosis: Anterior corpectomy and instrumentation, posterior fusion and instrumentation, combined anterior corpectomy plus posterior fusion and instrumentation. Albert ve ark. reported the effectiveness of the combined treatment. Miyazaki recommended the posterior instrumentation and fusion $(1,43)$. Gulmen and Zileli reported that anterior corpectomy was effective to decompress the spine and stabilization in compression mode with the use of bone grafts increased the fusion rates (27).

\section{Posttraumatic Kyphosis}

75 papers were found when the words 'posttraumatic' and 'kyphosis' were searched on Pubmed search engine. Majority of the papers discussed the surgical management.

Posttraumatic kyphosis usually occurs at the thoracolumbar junction. Kyphosis may occur following a spinal trauma and also after a surgery $(66,47)$. Segmental kyphosis might be caused by a height loss in the anterior column due to the loads applied to the thoracic region during compression and flexion. Progressive kyphosis can develop due to pseudoarthrosis that develops after the surgery performed to treat the spinal fractures of patients and due to lack of fusion. Although Kümmel's disease is a rare spinal disorder characterized as the 
posttraumatic osteonecrosis of the vertebral body, it may lead to progressive deformity (78). The exact surgical indications of the posttraumatic kyphosis are the progressive neurological deficit and pain.

\section{Surgery}

The primary goal in treating the posttraumatic kyphosis is to remove the existing neurological compression and bring the sagittal balance within the normal range. Anterior, posterior or combined approaches can be applied. Some papers reported that neither the anterior nor the posterior approach was superior to one another (7), whereas others claimed that neural decompression was easier with the anterior approach and deformity could be corrected easily $(32,33$, 47). The advantage of the anterior surgical approach over the posterior approach is that the former reduces the number of mobile segments which are to be included in the fusion (7).

Combined approach (anterior + posterior) can also be preferred and it is possible to achieve the sagittal balance in a single session by means of appropriate osteotomies to be chosen. Suk et al. claimed that osteotomy was a better alternative (62).

\section{Ankylosing Spondylitis}

Spondylarthropathies ( $\mathrm{SpA}$ ) are a group of systemic chronic inflammatory rheumatic diseases. SpA's are divided into five groups: Ankylosing spondylitis, pseudoarthrosis, reactive arthritis, arthritis associated with inflammatory bowel disease and undifferentiated spondylarthropathies. Ankylosing spondylitis affects the entire spine the most among the other groups $(5,16)$. Its prevalence ranges from $0.2 \%$ to $1.1 \%(5)$. Kyphosis with AS disrupts the whole sagittal balance. AS was first described by Vladimir von Bechterew in 1893 (6). AS involves the sacroiliac joint, entire spine, major joints (knee, hip, shoulder) and extra-articular elements (enthesitis and uveitis). It involves the thoracic and lumbar regions of the spine the most. Anderson described the aseptic spondylodiscitis for the first time in 1937. Spondylodiscitis causes erosive damage in the discs and vertebral bodies (2). Radiological images of patients with AS may reveal erosion in the bone, sclerosis, syndesmophytes, Anderson lesions (erosive discovertebral lesions), ankylosis (bamboo spine) and osteoporosis (36).

The most common symptoms of the patients include a pain in the whole spine, stiffness of the joints, limitation of movement and respiratory distress (5). Lumbar lordosis secondary to the increased thoracic kyphosis may decrease and cervical lordosis may be flattened (5). Horizontal gaze restriction might occur in patients due to the increased thoracic kyphosis (3, 4). The centre of mass in patients with ankylosing spondylitis shifts forward and downward $(3,4)$. The center of mass (COM) shifting forward is balanced by the extension of the hip, flexion of the knee and flexion of the wrinkle (4).

\section{Surgical Indications}

Surgery is required for only a few AS patients. Many patients can be managed by medical therapies and exercise. Surgery should be considered in case of pain and deformity progression despite the conservative treatment. Instable vertebral fractures, myelopathy developing due to progression of kyphosis and progressive spondylodiscitis are the absolute indications for surgery. The painful sagittal imbalance, loss of horizontal gaze, segmental instability are the relative surgical indications.

\section{Planning of the Osteotomy to Treat Ankylosing Spondylitis}

The main goal of surgery to treat AS patients is to restore the spinal balance and correct the chin-brow vertical angle (CBVA) $(38,62)$. In this way, the patient is again able to look straight ahead and the chin-chest impingement can be resolved. Osteotomy should planned very well. The patient may not be able to compensate the overcorrection. The mobility of the hip and knee joints should be taken into account prior to the surgery.

\section{For the correction in AS patients:}

1. Planning through standing lateral direct radiographic images: a translucent paper is placed on the lateral direct radiographic image. A plumb line is drawn from C2 downwards. The osteotomy site is identified (by a red line). Then the paper is cut along the line (Figure 1A). After that, the paper is rotated so that the plumb line intersects with the front of the sacrum. The $\mathrm{K}$ angle in between shows the osteotomy angle that needs to be corrected. At the end of the planning, dens should be on the vertical plane (Figure 1B).

2. Use of the lateral photographs of the patient: (72) The horizontal line drawn from the umbilicus is divided into three equal parts. A line is drawn starting from the line in the $1 / 3$ posterior part to the meatus acusticus externus. Another line is also drawn from the same $1 / 3$ posterior line to the lateral femoral condyle. The total of two angles corresponds to the whole body kyphosis angle. Whole body kyphosis angle (WBKA) reveals the angle that needs to be corrected. The chin-brow to vertical angle (CBVA) should always be kept in mind to avoid overcorrection (Figure 2).

\section{Congenital Kyphosis}

729 papers were found when the words 'congenital' and 'kyphosis' are searched on the Pubmed search engine. Those articles studying kyohoscoliosis, trauma, adolescence and adult types as well as those related to the syndromes were excluded from this review. 66 papers were analyzed in this review.

The term congenital kyphosis was first used in 1844. After James et al. published 21 series on congenital kyphosis, Van Schrick divided the congenital kyphosis into two types: failure of formation and failure of segmentation of the vertebral body $(30,67)$. Winter et al. classified congenital kyphosis under 3 main types $(71,72)$ : Failure of formation of the vertebral body (Type 1), failure of segmentation of the vertebral body (Type 2), formation failure with segmentation failure of the vertebral body (Mixed type-Type 3). This classification is important to determine the natural history of each type and identify the possible neurological deficits (19). 


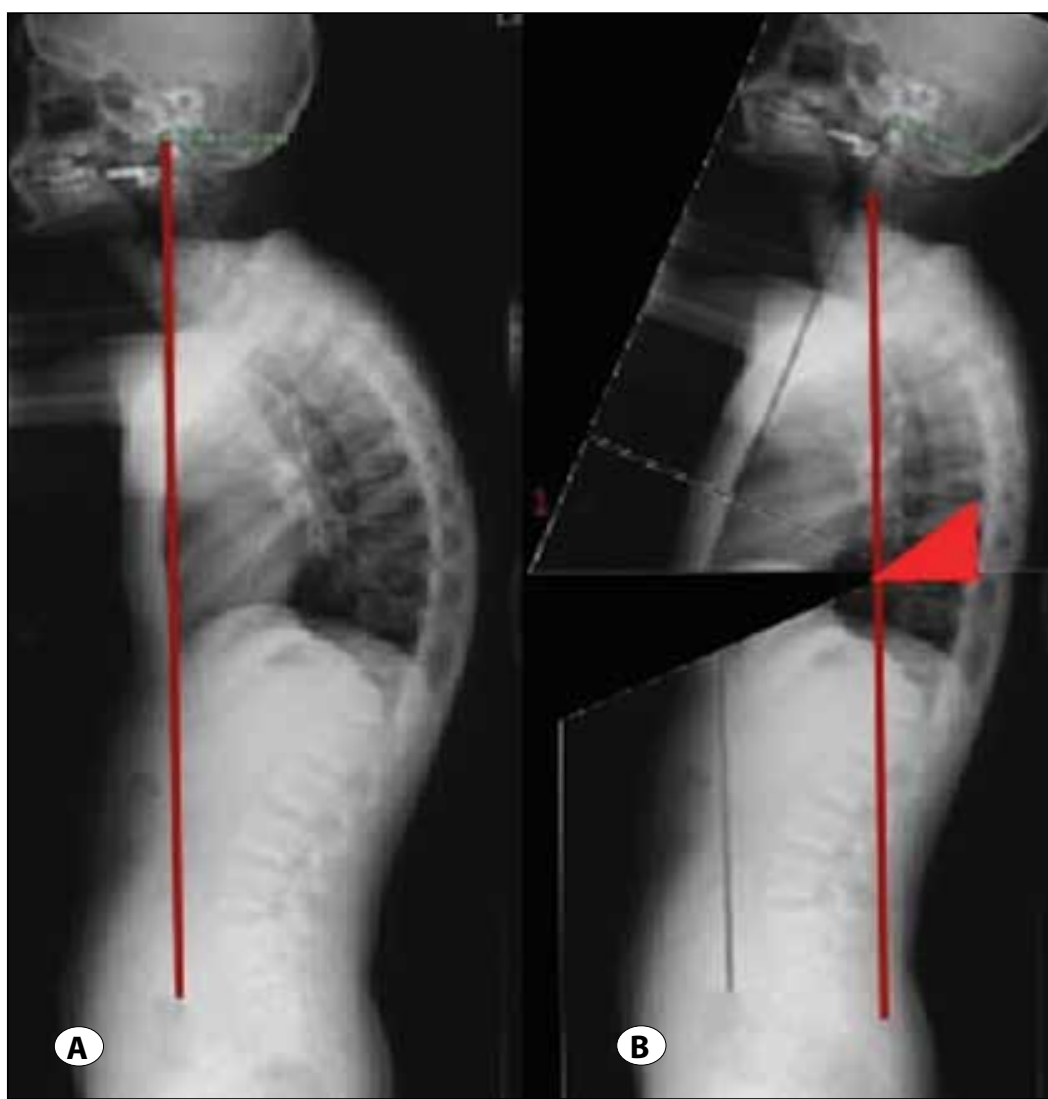

Figure 1: Planning the osteotomy level in ankylosing spondylitis cases by means of standing lateral direct radiographic images. A) A plumb line is drawn from C2 downwards. The osteotomy site is identified (by a red line). Then the paper is cut along the line. B) After that, the paper is rotated so that the plumb line intersects with the front of the sacrum. The $\mathrm{K}$ angle in between shows the osteotomy angle that needs to be corrected. At the end of the planning, dens should be on the vertical plane.

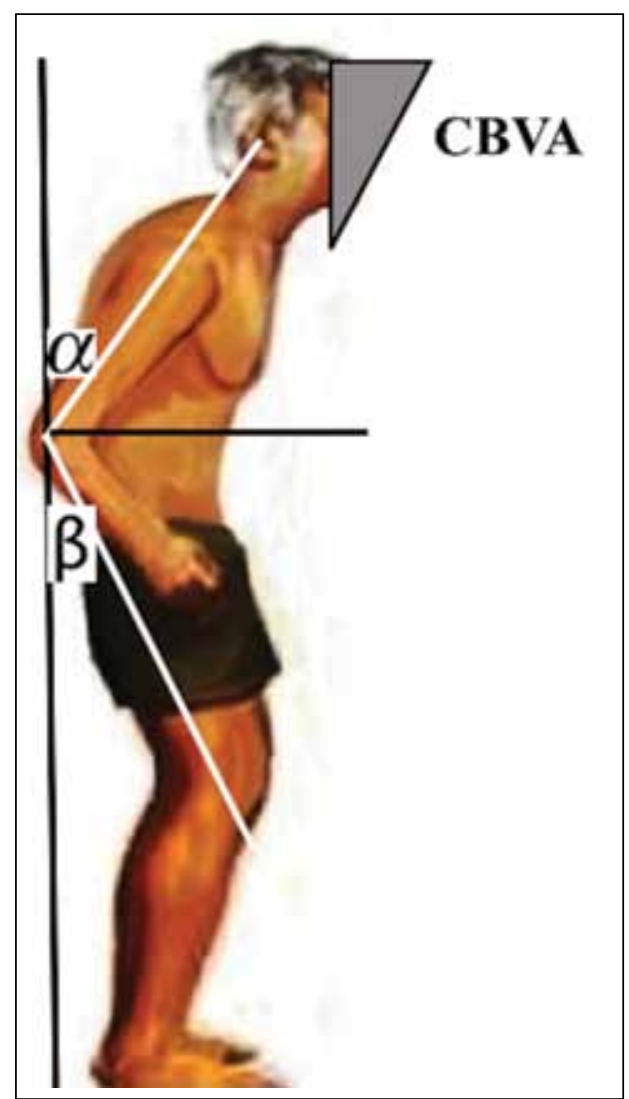

Figure 2: Using the lateral photograph of the patient to determine the level of osteotomy in case of ankylosing spondylitis.
It occurs in girls more than in boys. It can occur in any part of spinal column whereas apex is often located between T10 and L1 (42). The studies have shown that the degree of kyphosis increases during adolescence period while it is decelerated once one stops growing. Although Cobb angles are usually measured to follow up the progression of congenital kyphosis, they do not explain what happens to the apex of the curve $(21,68,73,74)$. Kyphosis caused by the formation failure of the vertebral body is more distinct, whereas kyphosis caused by the segmentation failure is vaguer.

Developmental anomalies of the vertebra occur during the chondrification and ossification stages (65). The longitudinal growth of the spine extends from the superior and inferior endplate epiphysis of the vertebral body (11). The vertebral rotation insufficiency of the growth plate in front of the transverse axis on the sagittal plane leads to congenital kyphosis (65). Hemivertebrae, butterfly vertebrae, and wedge vertebrae are formed due to the formation failure of the vertebral body. Longitudinal growth is achieved by the epiphysis in the superior and inferior endplates, which causes progressive kyphosis.

\section{Surgery}

Posterior fusion (without instrumentation, by stopping the growth of the convex side) will be adequate for the patients with Type 1 deformity, younger than 5 years of age and with a kyphotic angle lower than 50 degrees. Winter et al. argued that posterior fusion alone would be sufficient to control kyphosis and achieve the spinal alignment in patients younger than 5 years of age and with a kyphotic angle lower than 55 degrees $(73,74)$. Combined anterior and posterior surgery would be more suitable for the patients younger than 5 years of age and with a kyphotic angle greater than 55 degrees.

Winter and Moe proposed posterior fusion without correction for Type 2 deformities. The upper and lower vertebrae should be included in the fusion in case of segmentation failure of a vertebral body. (74). When there is a need for correction in later phases, combined anterior-posterior surgery should be preferred.

Paraplegia might develop during the correction of the kyphotic deformity. Lonstein stated that paraplegia developed more commonly in cases with rigid kyphotic apex (39). Blood 
supply to the spinal cord decreases during the extension and compression of the spine, which disturbs the venous return of the spinal cord and leads to oedema and ischemia in the spinal cord. Lonstein's series reported the highest number of neurological damage (seen in 42 out of 43 patients) (39). Winter and Montgomery reported that respectively $3 \%$ and $12 \%$ of patients developed paraplegia. One of the possible complications that might occur during the correction of the deformity is the pseudoarthrosis. Montgomery reported the rate of this complication as $7 \%$ whereas Winter stated this rate to be $41 \%$ in posterior approach alone, and $8 \%$ in combined approach $(74,44)$.

Growth stops as the childhood tuberculosis spondylitis damages the anterior portion of the vertebral body and kyphosis increasingly progresses until the end of the developmental age in line with the growth of the posterior column. The curve progression may lead to respiratory distress and neurological damage (50).

\section{Neuromuscular Kyphosis}

Neuromuscular kyphosis develops due to the neuropathic and myelopathic diseases. In NM diseases, kyphosis is usually accompanied by scoliosis. Lumbar hyperlordosis and pelvic imbalance accompany kyphoscoliosis. The treatment goal is to restore a spinal balance, increase the respiration capacity and relieve pain. The Scoliosis Research Society has divided NM deformities into 2 types: neuropathic and myopathic. Neuropathic deformities are characterized by the injury of the upper motor neurons; cerebral palsy, syringomyelia, spinal cord injury as well as the diseases of the lower motor neurons (poliomyelitis, spinal muscular atrophy). Duchenne's and Becker's muscular dystrophy is an example to the myopathic kyphoscoliosis. It is difficult to treat the NM kyphoscoliotic patients. Although Luque-Galveston technique had been used as a standard for the treatment of NM kyphoscoliosis by $90 \mathrm{~s}$, its complication rate was reported to be $50 \%$ (10). Wimmer et al. operated the patients with the LuqueGalveston and Isola instrumentation techniques and reported that they corrected the scoliotic curve by $54 \%$, pelvic tilt by $64 \%$ in Luque group while they corrected scoliosis and pelvic tilt by $57 \%$ and $63 \%$ respectively in the Isola group (70). Gaine et al. reported the same results as Luque and Isola for their DMD patients (25). The use of Cotrel-Dubousset (CD) systems eliminated the need for postoperative brace wear and diminished the risk of developing pseudoarthrosis (46). Tsirikos et al. stated that surgery led to less complication rates when unit rod system was used to treat the deformities that developed due to cerebral palsy, it was effective to correct the deformity and required less reoperation (64). The deformity that develops due to NM diseases has a large C shape and is accompanied by the pelvic obliquity. Limitations in movements and difficulty in sitting, cardiac and respiratory problems, weak bone structure of pelvis are the factors that make the surgery challenging.

The spinal column should be connected to the pelvis during the surgery. Combined anterior and posterior surgical approach facilitates the correction of the curve and prevents the risk of developing pseudoarthrosis. Pedicle screws are problematic for an osteoporotic spine. Therefore, every segmental level should be instrumented with thick screws to be able to enlarge the fusion area and facilitate the correction as three-column fixation is performed in the vertebrae. Sarwahi stated that pneumonia (0.7- 3.5\%), respiratory distress (9.2-24.1\%), urinary tract infection (0.7-5.3\%), surgical site infection (0.3-1.3\%) developed postoperatively in patients who underwent surgery due to NM deformities. It was found that the complication rates went up to $44-80 \%$ when the other complications caused by implant failure and gastrointestinal problems were added. Postoperative mortality rate was reported to be $7 \%(55)$.

One of the challenges in the surgery of NM kyphoscoliosis is the risk of high intraoperative blood loss (different from the surgery of other deformities). Many of these patients had been on antiepileptic medication, especially valproic acid. Valproic acid decreases the number of platelets and F8 levels (73). Even though the PT and APTT values are normal during the surgery, it has been understood that there is a high intraoperative blood loss during the surgery of the NM deformities compared to the other deformity types.

\section{Correction Osteotomies During the Surgery of Kyphosis}

\section{Smith-Peterson Osteotomy (Posterior column wedge oste-} otomy with opening of anterior column)

This is a correction osteotomy that was developed by SmithPeterson to correct the ankylosing spondylitis kyphosis (32, 33, $42,59)$. Besides, it can also be applied to treat posttraumatic kyphosis, flat-back syndrome and Scheuermann Kyphosis (35). Asymmetric SPO can also assist in restoring the balance (17). Both facet joints, lower portion of the superior vertebrae lamina and spinous process as well as flavum are removed in SPO, which is also known as "chevron" or "extension" osteotomy. The osteotomy space is closed with pedicle screws and lordosis is increased (17). The axis of rotation is moved to the posterior part of the disc space; in this way, the anterior part of the disc space is widened. This osteotomy is also referred to as extension osteotomy because of the widening of the disc's anterior part. At the end of the osteotomy, vertebral posterior column is shortened and the anterior column is extended (69). To perform SPO, the anterior disc space should be mobile. SPO cannot be performed in case of a fixed kyphosis with an osteophyte in the anterior part. Every $1 \mathrm{~mm}$ - widening achieves 1-degree lordosis through SPO osteotomy. On average 10-degree correction can be achieved in each SPO osteotomy $(18,20)$. After opening the disc space and neuronal foramens with a support inserted in the $1 / 3$ anterior or middle parts of the disc space, the support can be used as a lever arm to lean the spine back (Figure 3,4). Lordosis can be achieved easily without narrowing the neural foramens.

\section{Is SPO required for the patient?}

Before deciding on SPO for a patient with kyphotic deformity, 
it should be investigated whether the curve is flexible or not. To this end, the radiographic image should be obtained in the supine position by placing a support to the apex of kyphosis. If the curve flattens, then osteotomy is not required. If the curve does not flatten despite the support, then SPO is required. However, if there are osteophytes in the anterior part of the disc in the direct radiography, SPO is contraindicated $(17,69)$. Booth et al. divided the deformity in the sagittal balance into 2 types. The Type 1 kyphotic deformity is compensated with the other mechanisms of the spine. Type 2 deformities cannot be balanced by the hyperextension mechanisms of the spine (13). Bridwell used this classification and stated that SPO could be performed to correct Type 1 kyphosis which was located in the thoracic region, long and had little curve and Type 2 kyphosis with minimal positive sagittal balance $(6-8 \mathrm{~mm})$ to achieve the sagittal balance. However, he reported that SPO was contraindicated to sharp-angled Type 2 kyphosis (17). Bridwell claimed that SPO should be avoided unless the Zielke method was used (multiple SPO from T10 to the sacrum) for the patients with ankylosing spondylitis.

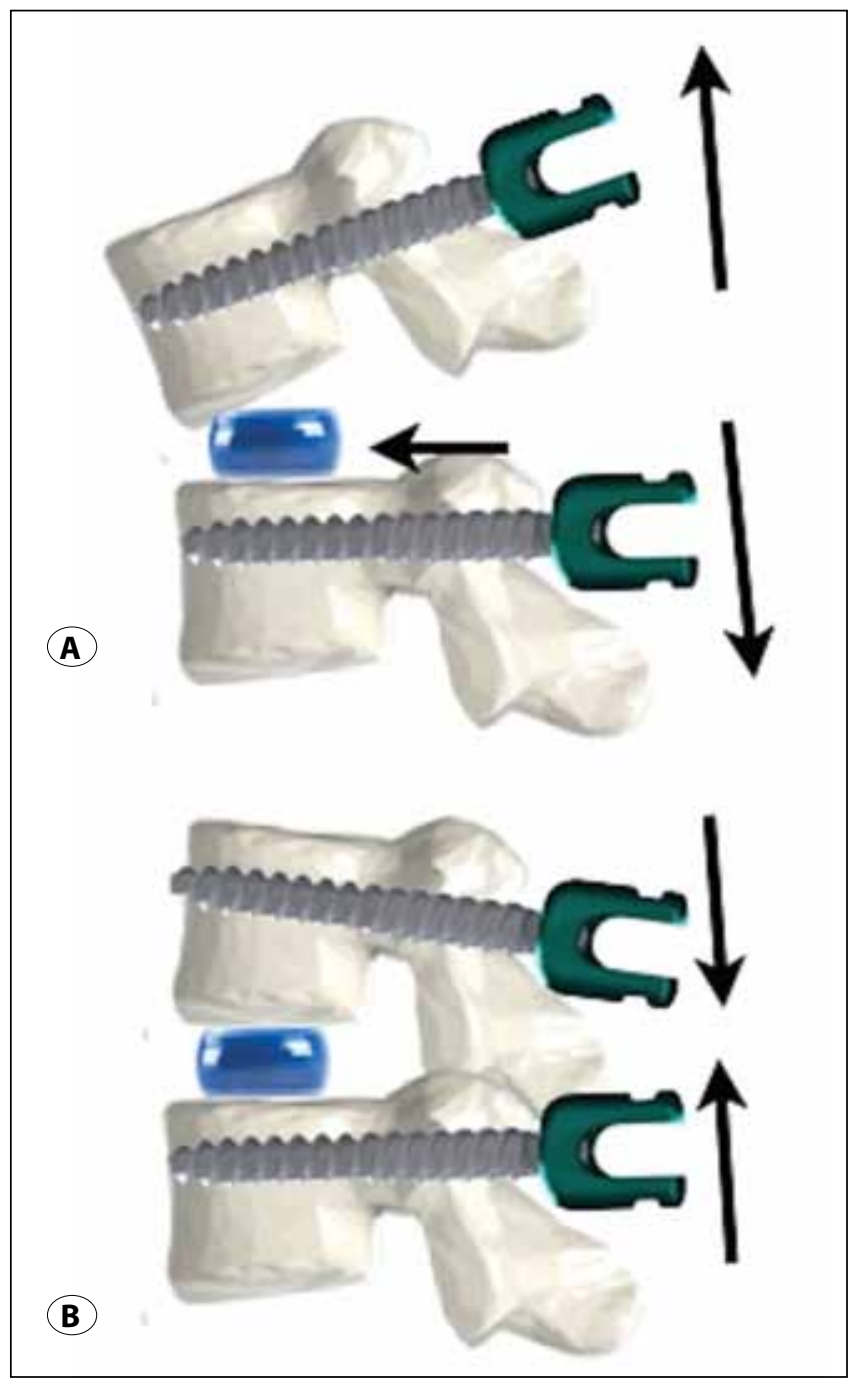

Figure 3: Closure of the osteotomy site by placing a support to the disc space.
The more distal the osteotomy level in the spin, the greater impact it has on the global sagittal balance (the plumb line of C7 intersects with the posterior part). For instance, L5-S1 osteotomy achieves greater correction than L1-2 osteotomy.

\section{For which patients should SPO be preferred?}

Scheuermann Kyphosis: In this group of patients, surgery is performed by anterior loosening whereas although posterior fusion is performed, SPO with posterior instrumentation and fusion surgeries was demonstrated to be effective to correct kyphosis instead of 360 degree fusion (37).

Flat-back Syndrome: The flat-back syndrome that happens after the thoracolumbar scoliosis surgery occurs due to the loss of lumbar lordosis. Sagittal balance can be restored with SPO below the conus level if there is no thoracic kyphosis in patients and on the apex of kyphosis if there is a thoracic kyphosis $(49,69)$.

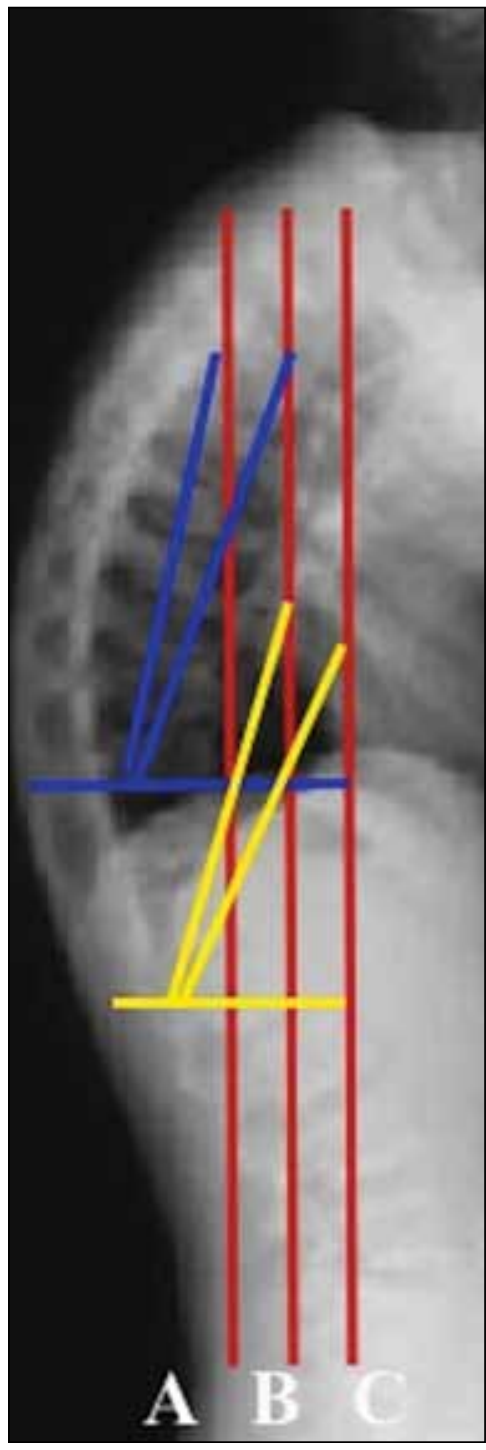

Figure 4: Relation between the level selected for osteotomy and the global sagittal balance correction. 


\section{Ponte Osteotomy (Posterior Closing Wedge Osteotomy)}

This type of wedge osteotomy was first descriped in 1984 by Alberto Ponte for the treatment of Scheuermann's Kyphosis

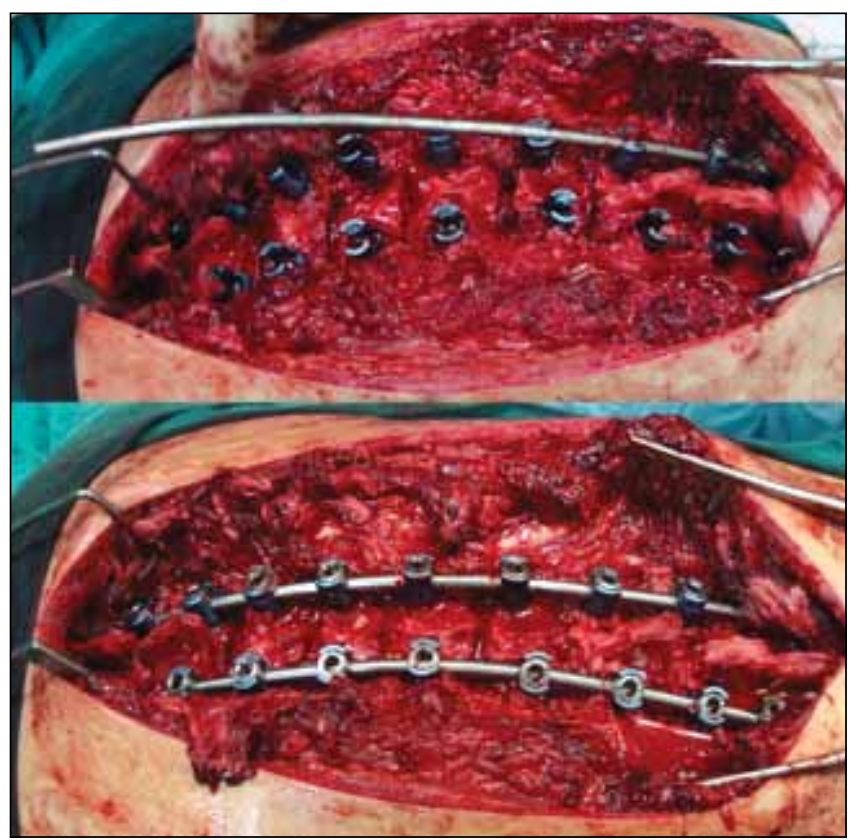

Figure 5: Ponte osteotomy for Scheuermann's Kyphosis (76) (Reprinted with permission).
(48). Inferior articular processes of the cephalad vertebra and the superior articular processes of the caudal vertebra and also ligamentum flavum and interspinous ligament has to be removed to perform Ponte Osteotomy (58). Posterior column shortens with closing the posterior part of the vertebrae. Ponte osteotomy can yield 5 to 15 of correction per level (26). A mobile anterior column is needed to perform Ponte osteotomy. Shufflebarger et al. also used Ponte osteotomy for the correction of adult idiopathic scoliosis (58). Ponte osteotomy is a fast, safe, and effective technique when compared to other complex osteotomy types. Ponte osteotomy decreases also blood loss, surgery time and has also less neurologic risk (Figure 5).

\section{Pedicle Subtraction Osteotomy (Three-Column Closing- Wedge Posterior Osteotomy)}

This type of osteotomy was first described by Thomasen in 1985 (63). Pedicle subtraction osteotomies are used to correct kyphosis that develops due to congenital, posttraumatic, metabolic, infectious causes. High morbidity rates were reported in patients operated with PSO $(29,54,78)$. Pedicle subtraction osteotomy is usually performed on L2 or L3 level. The reason why it is most commonly used for these two levels is that they are located distal to the conus medullaris, they are more risk-free and they form the apex of the lumbar lordosis. Approximately 30-40 degree lordosis is gained by pedicle subtraction osteotomy $(17,18)$. Prior to the pedicle

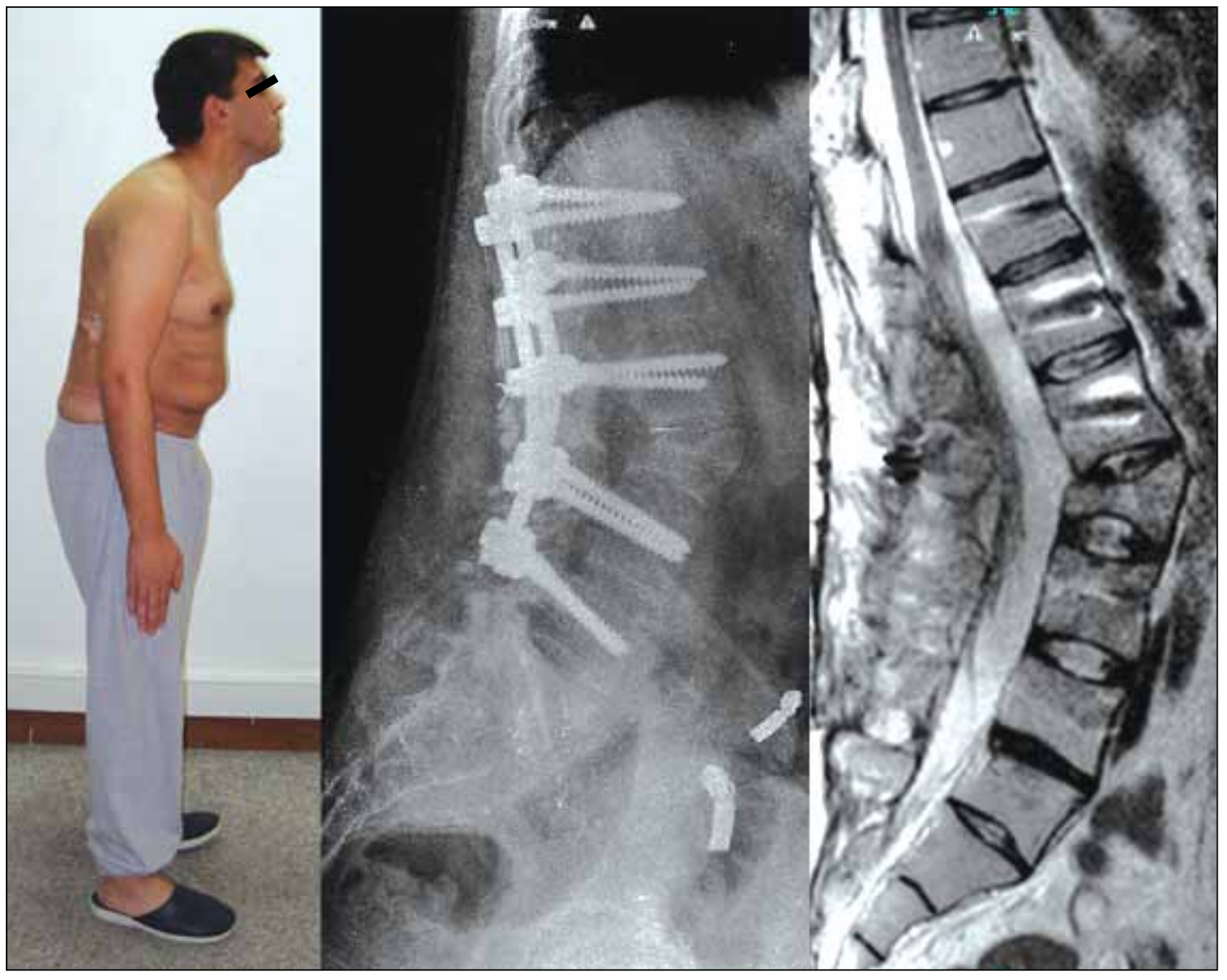

Figure 6:

Pedicle subtraction osteotomy for ankylosing spondylitis (76) (Reprinted with permission). 
subtraction osteotomy, screws should be inserted to the pedicles of the superior and inferior vertebrae. All posterior elements of the level where PSO will be performed should be removed. After entering the corpus of the vertebra by means of the pedicle, the dorsal cortex of the vertebrae should be fractured. Some part of the vertebrae should remain in the ventral area for support. Both sides of the vertebra corpus should be removed equally and symmetrical closure should be performed during the closing procedure. The space opened for PSO can be closed without applying a force by the hyperextension of the surgical table (Figure 6).

\section{Vertebral Column Resection}

Vertebral column resection (VCR) was first described in 1922. One or more vertebrae are removed by combined anterior-posterior or posterior alone approach (62). Suk et al. developed the posterior alone intervention technique for VCR and stated that VCR with this technique lasted shorter and the complication rates were low compared to the combined approach (62).

\section{CONCLUSIONS}

Every patient with kyphosis should be treated based on her/ his current state and needs. It should always be remembered that the patients with negative sagittal balance can compensate it with the hip flexion but it is far more difficult to compensate the positive sagittal balance. The patients should be investigated well by hip flexors prior to surgery to see if they have any contractures. The main goal of surgery to treat the kyphotic patients is to correct the sagittal curve and also restore a spinal balance within an acceptable range above the hips and knees.

\section{REFERENCES}

1. Albert TJ, Vacarro A: Postlaminectomy kyphosis. Spine 23: 2738-2745, 1998

2. Anderson PA, Matz PG, Groff MW, Heary RF, Holly LT, Kaiser MG, Mummaneni PV, Ryken TC, Choudhri TF, Vresilovic EJ, Resnick DK: Laminectomy and fusion for the treatment of cervical degenerative myelopathy. J Neurosurg Spine 11: 150-156, 2009

3. Appel $H$, Kuhne $M$, Spiekermann $S$, Ebhardt $H$, Grozdanovic Z, Kohler D, Dreimann M, Hempfing A, Rudwaleit M, Stein H, Metz-Stavenhagen P, Sieper J, Loddenkemper C: Immunohistologic analysis of zygapophyseal joints in patients with ankylosing spondylitis. Arthritis Rheum 54: 2845-2851, 2006

4. Aufdermaur M: Pathogenesis of square bodies in ankylosing spondylitis. Ann Rheum Dis 48:628-631, 1989

5. Baraliakos X, Hermann KG, Landewe R, Listing J, Golder W, Brandt J, Rudwaleit M, Bollow M, Sieper J, van der Heijde $D$, Braun J: Assessment of acute spinal inflammation in patients with ankylosing spondylitis by magnetic resonance imaging: A comparison between contrast enhanced T1 and short tau inversion recovery (STIR) sequences. Ann Rheum Dis 64: $1141-1144,2005$
6. Bechterew W: Steifigkeit der Wirbelsäule und ihre Verkrümmung als besondere Erkankungsform. Neurol Centralblatt 12:426-434, 1893

7. Been HD, Poolman RW, Ubags LH: Clinical outcome and radiographic results after surgical treatment of posttraumatic thoracolumbar kyphosis following simple type $\mathrm{A}$ fractures. Eur Spine J 13:101-107, 2004

8. Bell OF, Walker JL, O'Connor: Spinal deformity following multiple laminectomy in children (abs). Presented at the 56th Annual Meeting of the American Academy of Orthopaedic Surgeons, Las Vegas, 1989

9. Bernhardt M, Bridwell KH: Segmental analysis of the sagittal plane alignment of the normal thoracic and lumbar spines and thoracolumbar junction. Spine 14: 717-721, 1989

10. Benson ER, Thomson JD, Smith BG, Banta JV: Results and morbidity in a consecutive series of patients undergoing spinal fusion for neuromuscular scoliosis. Spine 23: 2308-2318, 1998

11. Bick EM, Copel JW: Longitudinal growth of the human vertebra. A contribution to human osteogeny. J Bone and Joint Surg 32-A: 803-814, 1950

12. Blumenthal SL, Roach J, Herring JA: Lumbar Scheuermann's. A clinical series and classification. Spine 9:929-932, 1987

13. Booth KC, Bridwell KH, Lenke LG, Baldus CR, Blanke KM: Complications and predictive factors for the successful treatment of flatback deformity (fixed sagittal imbalance). Spine 24:1712-1720, 1999

14. Bouley C, Tardieu C, Hecquet J, Benaim C, Mouilleseaux B, Marty C, Prat-Pradal D, Legaye J, Duval-Beaup'ere G, P'elissier $\mathrm{J}$ : Sagittal alignment of spine and pelvis regulated by pelvic incidence: Standard values and prediction of lordosis. Eur Spine J 15:415-422, 2006

15. Bradford DS, Moe JH, Montalvo FJ, Winter RB: Scheuermann's kyphosis. Results of surgical treatment by posterior spine arthrodesis in twenty-two patients. J Bone Joint Surg (Am) 57A: 439-448, 1975

16. Braun J, van der Heijde D: Imaging and scoring in ankylosing spondylitis. Best Pract Res Clin Rheumatol 16:573-604, 2002

17. Bridwell KH: Decision making regarding Smith-Petersen vs. pedicle subtraction osteotomy vs. vertebral column resection for spinal deformity. Spine 31:S171-S178, 2006

18. Bridwell KH: Osteotomies for fixed deformities in the thoracic and lumbar spine. In: Bridwell KH, DeWald RL (eds). The Textbook of Spinal Surgery, 2nd ed. Philadelphia:LippincottRaven, 1997:821-835

19. Chambers HG, Weinstein CH, Mubarak SJ, Wenger DR, Silva PD: The effect of valproic acid on blood loss in patients with cerebral palsy. J Pediatr Orthop 19:792-795, 1999

20. Cho KJ, Bridwell KH, Lenke LG, Berra A, Baldus C: Comparison of Smith- Petersen versus pedicle subtraction osteotomy for the correction of fixed sagittal imbalance. Spine 30: 2030-2038, 2005

21. Cobb JR: Outline for the study of scoliosis. In: instructional course lectures. American Academy of Orthopaedic Surgeons 5:261-275, 1948 
22. Dickson JH, Harrinoton PR, Erwin WD: Results of reduction and stabilization of the severely fractured thoracic and lumbar spine. J Bone and Joint Surg 60-A: 799-805, 1978

23. Edgren W, Vainio S: Osteochondrosis juvenilis lumbalis. Acta Chir Scand Suppl 227:3-47, 1957

24. Epstein JA: The surgical management of cervical spinal stenosis, spondylosis and myeloradiculopathy by means of the posterior approach. Spine 13: 864-869, 1998

25. Gaine WL, Lim J, Stephenson W: Progression of scoliosis after spinal fusion in Duchenne's muscular dystrophy. J Bone Jt Surg 86B:550-555, 2004

26. Geck MJ, Macagno A, Ponte A, Shufflebarger HL: The Ponte procedure: Posterior only treatment of Scheuermann's kyphosis using segmental posterior shortening and pedicle screw instrumentation. J Spinal Disord 20(8): 586-593, 2007

27. Gulmen V, Zileli M: Surgical treatment of post laminectomy cervical kyphosis. Turkish Neurosurgery 10: 28 - 35, 2000

28. Herkowitz HN: A comparison of anterior cervical fusion, cervical laminectomy, and cervical laminoplasty for the surgical management of multiple level spondylotic radiculopathy. Spine (Phila Pa 1976) 13:774-780, 1998

29. Hosman AJ, Langeloo DD, de Kleuver M, Anderson PG, Veth RP, Slot GH: Analysis of the sagittal plane after surgical management for Scheuermann's disease: A view on overcorrection and the use of an anterior release. Spine 2:167-175, 2002

30. James J: Kyphoscoliosis. J Bone Joint Surg Br 37B: 414-426, 1955

31. Kelly RP, Whitesideste Jr: Treatment of lumbodorsal fracturedislocations. Ann Surg 167: 705-717, 1968

32. Kostuik JP, Maurais GR, Richardson WJ, Okajima Y: Combined single stage anterior and posterior osteotomy for correction of iatrogenic lumbar kyphosis. Spine 13:257-266, 1998

33. Kostuik JP, Matsusaki H: Anterior stabilization, instrumentation, and decompression for post-traumatic kyphosis. Spine 14(4):379-386, 1989

34. Kumar VG, Rea GL, Mervis LJ, McGregor JM: Cervical spondylotic myelopathy: Functional and radiographic longterm outcome after laminectomy and posterior fusion. Neurosurgery 44:771-777, 1999

35. Lagrone MO, Bradford DS, Moe JH, Lonstein JE, Winter RB, Ogilvie JW: Treatment of symptomatic flatback after spinal fusion. J Bone Joint Surg Am 70:569-580, 1988

36. Lambrecht V, Vanhoenacker FM, Van Dyck P, Gielen J, Parizel PM: Ankylosing spondylitis: What remains of the standard radiography anno 2004. JBR-BTR 88:25-30, 2005

37. Lee SS, Lenke LG, Kuklo TR, Valenté L, Bridwell KH, Sides B, Blanke KM: Comparison of Scheuermann kyphosis correction by posterior-only thoracic pedicle screw fixation versus combined anterior/posterior fusion. Spine 31:2316-2321, 2006

38. Legaye J, Duval-Beaupere G, Hecquet J, Marty C: Pelvic incidence: A fundamental pelvic parameter for threedimensional regulation of spinal sagittal curves. Eur Spine J 7: 99-103, 1998
39. Lonstein JE: Cord compression. In: Moe JH, Lonstein JE, Bradford DS (eds), Moe's Textbook of Scoliosis and other Spinal Deformities, 3rd ed. Philadelphia: WB Saunders, 1995:534-540

40. Lowe TG, Kasten MD: An analysis of sagittal curves and balance after Cotrel-Dubousset instrumentation for kyphosis secondary to Scheuermann's disease. A review of 32 patients. Spine 19(15):1680-1685, 1994

41. McAllister BD, Rebholz BJ, Wang JC: Is posterior fusion necessary with laminectomy in the cervical spine? Surg Neurol Int 3(Suppl 3): S225-S231, 2012

42. McMaster MJ: A technique for lumbar spinal osteotomy in ankylosing spondylitis. J Bone Joint Surg Br 67:204-210, 1985

43. Miyazaki K, Tada K, Matsuda Y, Okuno M, Yasuda T, Murakami $\mathrm{H}$ : Posterior extensive simultaneous multisegmental decompression with posterolateral fusion for cervical instability and kyphotic and/or S-shaped deformities. Spine 14:1160-1170, 1989

44. Montgomery SP, Hall JE: Congenital kyphosis. Spine 7: 360-364, 1982

45. O'Brien MF, Kuklo TR, Blanke KM, Lenke LG: Radiographic Measurement Manual. Medtronic Sofamor Danek USA, Inc., 2004:1-110

46. Onimus M, Manzone P, Lornet JM, Laurain JM: Surgical treatment of scoliosis in bed-ridden patients with cerebral palsy. Rev Chir Orthop Reparatrice Appar Mot 78:312-318, 1992

47. Polly DW Jr, Klemme WR, Shawen S: Management options for the treatment of posttraumatic thoracic kyphosis. Semin Spine Surg 12:110-116, 2000

48. Ponte A, Vero B, Siccardi G: Surgical treatment of Scheuermann's hyperkyphosis. In: Winter R, (ed), Progress in Spinal Pathology: Kyphosis. Bologna, Aulo Gaggi, 1984:75-81

49. Potter BK, Lenke LG, Kuklo TR: Prevention and management of iatrogenic flatback deformity. J Bone Joint Surg Am 86-A:1793-1808, 2004

50. Poussa MS, Heliövaara MM, Seitsamo JT, Könönen $M H_{\text {, }}$ Hurmerinta KA, Nissinen MJ: Anthropometric measurements and growth as predictors for low-back pain: A cohort study of children followed up from the age of 11 to 22 years. Eur Spine J 14:595-598, 2005

51. Raimondi AJ, Gutierrez FA, Di Rocco C: Laminotomy and total reconstruction of the posterior spinal arch for spinal canal surgery in childhood. J Neurosurg 45: 555-560, 1976

52. Rao RD, Madom IA, Wang JC editors. Cervical laminectomy and fusion. Advanced reconstruction spine. American Academy of Orthopedic Surgeons 2011:97-104

53. Riddle EC, Bowen JR, Shah SA, Moran EF, Lawall H Jr: The duPont kyphosis brace for the treatment of adolescent Scheuermann kyphosis. J South Orthop Assoc 12(3):135-140, 2003

54. Sachs B, Bradford D, Winter R, Lonstein J, Moe J, Willson $\mathrm{S}$ : Scheuermann kyphosis. Follow-up of Milwaukee-brace treatment. J Bone Joint Surg Am 69:50-57, 1987 
55. Sarwahi V, Sarwark JF, Schafer MF, Backer C, Lee M, King EC, Aminian A, Grayhack JJ: Standards in anterior spine surgery in pediatric patients with neuromuscular scoliosis. J Pediatr Orthop 21:756-760, 2001

56. Scioscia T, Crowl AC, Wang JC: Posterior subaxial cervical fusion. Advanced reconstruction spine. American Academy of Orthopedic Surgeons 2011:89-95, 2011

57. Scheuermann HW: Kyphosis dorsalis juvenilis. Ugeskr Laeger 82:385-393, 1920

58. Shufflebarger HL, Clark CE: Effect of wide posterior release on correction in adolescent idiopathic scoliosis. J Pediatr Orthop B 7(2):117-123, 1998

59. Smith-Petersen MN, Larson CB, Aufranc OE: Osteotomy of the spine for correction of deformity in rheumatoid arthritis. Clin Orthop Relat Res 66:6-9, 1969

60. Sörensen KH: Scheuermann's juvenile kyphosis. Copenhagen: Munksgaard, 1964

61. Stagnara P, De Mauroy JC, Dran G, Gonon GP, Costanzo G, Dimnet J, Pasquet A: Reciprocal angulation of vertebra bodies in a sagittal plane: Approach to references for the evaluation of kyphosis and lordosis. Spine 7:335-342, 1982

62. Suk SI, Kim JH, Lee SM, Chung ER, Lee JH: Anterior-posterior surgery versus posterior closing wedge osteotomy in posttraumatic kyphosis with neurologic compromised osteoporotic fracture. Spine 28(18):2170-2175, 2003

63. Thomasen E: Vertebral osteotomy for correction of kyphosis in ankylosing spondylitis. Clin Orthop Relat Res 194:142-152, 1985

64. Tsirikos Al, Chang W, Dabney K, Miller F, Glutting J: Life expectancy in pediatric patients with cerebral palsy and neuromuscular scoliosis who underwent spinal fusion. Dev Med Child Neurol 45:677-682, 2003

65. Tsou PM, Yau A, Hodgson AR: Embryogenesis and prenatal development of congenital vertebral anomalies and their classification. Clin Orthop 152: 211-231, 1980

66. Vaccaro AR, Jacoby SM:Thoracolomber fractures. Orthopaedic Knowledge Update Spine 2 (eds), American Academy of Orthopedic Surgeons, 2002:263-278
67. van Schrick FG: Die angeborene kyphose. Z Orthop Chir 56: 238-243, 1932

68. Voutsinas SA, MacEwen GD: Sagittal profiles of the spine. Clin Orthop 210: 235-242, 1986

69. Wiggins GC, Ondra SL, Shaffrey Cl: Management of iatrogenic flat-back syndrome. Neurosurg Focus 15:E8, 2003

70. Wimmer C, Wallnofer P, Walochnik N, Krismer M, Saraph V: Comparative evaluation of Luque and Isola instrumentation for treatment of neuromuscular scoliosis. Clin Orthop Relat Res 439:181-192, 2005

71. Winter RB, Moe JH, Wang JF: Congenital kyphosis: Its natural history and treatment as observed in a study of one hundred and thirty patients. J Bone Joint Surg Am 55: 223-256, 1973

72. Winter RB: Congenital kyphosis. Clin Orthop Relat Res 128: 26-32, 1977

73. Winter SL, Kriel RL, Novacheck TF, Luxenberg MG, Leutgeb VJ, Erickson PA: Perioperative blood loss: The effect of valproate. Pediatr Neurol 15:19-22, 1996

74. Winter RB, Moe JH, Lonstein JE: The surgical treatment of congenital kyphosis: A review of 94 patients age 5 years or older, with 2 years or more follow-up in 77 patients. Spine 10: 224-231, 1985

75. Wimmer C, Wallnöfer P, Walochnik N, Krismer M, Saraph V: Comparative evaluation of Luque and Isola instrumentation for treatment of neuromuscular scoliosis. Clin Orthop Relat Res 439:181-192, 2005

76. Yaman O, Dalbayrak S: Kyphosis: Diagnosis, classification and treatment methods. Turk Neurosurg 24(Supplement: 1): 6274,2014

77. Yasouka S, Peterson HA, MacCarty CS: Incidence of spinal column deformity after multileyel laminectomy in children and adults. J Neurosurg 57: 441-445, 1982

78. Young WF, Brown D, Kendler A, Clements D: Delayed posttraumatic osteonecrosis of a vertebral body (Kummell's disease). Acta Orthop Belg 68:13-19, 2002

79. Zdeblick TA, Bohlman HH: Myelopathy, cervical kyphosis and treatment by anterior corpectomy and strut grafting. J Bone Joint Surg (Am) 71: 170-182, 1989 